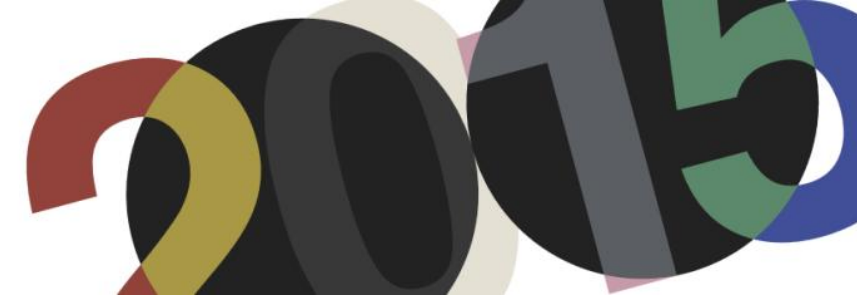

DOI: http://dx.doi.org/10.4995/LC2015.2015.661

\title{
"L'emploi du quatrième mur sur le pan de verre". Apariciones del concepto de cuarta pared en los libros, textos y documentos de Le Corbusier
}

\author{
J.A. Rodríguez Casas \\ Escuela Técnica Superior de Arquitectura de Madrid
}

\begin{abstract}
Resumen: La cuarta pared de Le Corbusier es un modelo teórico que ve por primera vez la luz en La Ville Radieuse en 1935. Su aparición, tras la fachada libre, abre el campo de posibilidades de diseño del cerramiento de los edificios tras la fachada libre. Desde su primer enunciado, la teoría tiene un carácter eminentemente práctico, ya que define con claridad un conjunto de instrucciones y una herramienta de proyecto. Esta herramienta permite el diseño de cerramientos de vidrio divididos de acuerdo a la geometría del Modulor, siendo capaz cada una de estas divisiones de asumir una función diferente (ventilación, iluminación, vistas). Además, mediante el aumento del espesor de la fachada, la herramienta de la cuarta pared posibilita alojar módulos de equipamiento en su interior, disponer el vidrio en distintas posiciones de protección o exposición e incluso colocar pantallas y capas de protección dentro del espesor del cerramiento. Aunque tuvo escasas apariciones en los escritos de Le Corbusier, la teoría fue en su vertiente práctica de uso frecuente en el estudio de Rue de Sèvres, 35 tanto en proyectos como en edificios construidos. El presente trabajo recorre la presencia de la cuarta pared en los escritos del arquitecto y analiza el contenido de la misma, intentando desentrañar el "manual de instrucciones" que supone. El artículo sintetiza además la deriva que sufrió la cuarta pared a lo largo de la carrera del arquitecto, poniendo de manifiesto su capacidad de adaptación al avance técnico constante en su arquitectura.
\end{abstract}

\begin{abstract}
Le Corbusier's fourth wall is a theoretical model that first appears in "La Ville Radieuse" in 1935, opening, after the free façade, a full range of possibilities to the design of the building's envelope. It has mainly a practical character from its first wording, as the fourth wall clearly defines a set of instructions and a tool for projecting, The tool allows for the enclosures to be divided according the Modulor's geometry, with each of these divisions being able to take on different functions (ventilation, illumination or views). In addition to this, the fourth wall's tool is able to accommodate equipment modules inside the façade by increasing its thickness, place the glass in different protection or exposure positions or even placing screens or protection layers inside the building envelope's thickness. While the theory seldom appeared in Le Corbusier's writings, it was frequently used by the Rue de Sèvres 35 office due to its practical implications, either in projects or in completed buildings. The present work visits and analyses the fourth wall's few appearances in the architect's theoretical documents and attempts to untangle its "instruction manual. The article summarises as well the drift that the fourth wall theory experimented through the architect's career, evidencing its ability to adapt to the constant technical development of his architecture.
\end{abstract}

Palabras clave: quatrième mur, cuarta pared, façade libre, fachada libre, pan de verre. Keywords: quatrième mur, fourth wall, façade libre, free façade, pan de verre.

\section{Introducción. Objetivos y antecedentes.}

El presente trabajo toma como objeto de estudio la figura de la cuarta pared de Le Corbusier. Se trata de una teoría o modelo que abrió el campo de posibilidades de diseño del cerramiento de los edificios en el contexto de la entonces reciente introducción del concepto de la fachada libre, no sujeta ya a las servidumbres de su tradicional función estructural. El artículo tiene la voluntad de sentar la base documental sobre la que acometer un estudio más profundo de la teoría, que venga a paliar en la medida de lo posible la desproporción entre la poca atención recibida por la misma y el extenso uso que se hizo de la misma a modo de herramienta de proyecto en la práctica del estudio del 35, Rue de Sèvres. 
La cuarta pared de Le Corbusier no ha tenido hasta la fecha un tratamiento monográfico de relevancia, encontrándose tan solo alusiones aisladas a la teoría, en su mayor parte en monografías de obras de Le Corbusier en cuyo diseño el papel de la herramienta de la cuarta pared fue decisivo ${ }^{1}$, si bien nunca han supuesto un estudio de profundidad sobre la herramienta. Recientemente la teoría ha aparecido mencionada en estudios sobre el arquitecto no centrados en una obra concreta, sino desde su componente de estrategia de introducción del equipamiento de la vivienda en el cerramiento en Le Corbusier, Furniture and interiors 1905-65 y desde el punto de vista de sus características plásticas y materiales en Le Corbusier: Béton Brut and ineffable space $e^{3}$.

Existe de todos modos una excepción a esta situación, y es a partir de la misma que este trabajo toma forma. En la tesis doctoral La densidad del limite. Le Corbusier y Mies Van Der Rohe del equipamiento al sistema de objetos $^{4}$ de Carmen Martínez Arroyo, se realiza un ejercicio de análisis y formulación de la teoría de la cuarta pared ${ }^{5}$, fruto del estudio del cerramiento del edificio en la arquitectura moderna focalizado en (pero no limitado a) las figuras de Le Corbusier y Mies van der Rohe. El presente artículo se encuentra englobado dentro de la investigación de mi tesis doctoral La cuarta pared de Le Corbusier, sistema de densificación del cerramiento del edificio, codirigida por Carmen Martínez Arroyo y planteada como continuación de la mencionada línea de investigación de su tesis, a modo de spin-off..

\section{El manifiesto oculto de le quatrième mur $^{6}$ en La Ville Radieuse ${ }^{7}(1935)$.}

La cuarta pared de Le Corbusier no fue presentada de manera concisa y directa, ni arropada en una conferencia o artículo sobre el particular que comunicara con claridad su contenido y naturaleza. Al contrario que en muchas otras ocasiones en la labor teórico-propagandística de Le Corbusier, la presentación de la teoría o herramienta se realiza de manera callada, casi subrepticia. La cuarta pared aparecerá como un simple dibujo a línea en página

\footnotetext{
${ }^{1}$ A destacar los apartados dedicados al particular en los trabajos monográficos Maniaque, Caroline: Le Corbusier et Les maisons Jaoul. Projets et fabrique Paris: Éditions A. \& J. Picard, 2005, pp. 76-83 y Sbriglio, Jacques, Immeuble 24 N.C. et Appartement Le Corbusier. Basel: Birkhäuser, 1996, pp.64-66.

${ }^{2}$ Rüegg, Arthur, Le Corbusier, Furniture and Interiors 1905-1965. Zürich, Verlag Scheidegger and Spiess, 2012

${ }^{3}$ Gargiani, Roberto; Rosellini, Anna: Le Corbusier: Béton Brut and Ineffable Space, 1940-1965: Surface Materials and Psychophysiology of Vision. Lausanne: EPFL Press - Oxford: Routledge, 2011

${ }^{4}$ Martínez Arroyo, Carmen: La densidad del límite. Le Corbusier y Mies Van Der Rohe del equipamiento al sistema de objetos. Director: Manuel de las Casas. Universidad Politécnica de Madrid, Escuela Técnica Superior de Arquitectura de Madrid, Departamento de Proyectos Arquitectónicos, 2005

${ }^{5}$ Ver también resumen de la tesis en el artículo Martínez Arroyo, Carmen: "La densidad del límite". En Arquitectos n 174 , Volumen 05/2. Madrid: CSCAE 2005

${ }^{6}$ Se opta en adelante por la traducción la cuarta pared frente a la más literal del cuarto muro en atención a la memoria de significado teatral del término le quatrième mur en la cultura francesa en el momento de la aparición de la teoría. El término hacía referencia a una hipotética cuarta pared dentro de la caja escénica coincidente con la separación de escenario y platea, y plantea una completa teoría escénica en función del uso que se hacía de la cuarta pared, bien desarrollándose la acción teatral como si dicho muro fuera real, o bien forzando su ruptura mediante la interpelación directa de los actores a la audiencia extendiendo la acción más allá de los límites físicos de la caja escénica. El termino se considera acuñado por André Antoine en el siglo XIX pero ya Diderot lo describía en sus escritos un siglo antes; en cualquier caso la ruptura de la cuarta pared es un hecho teatral establecido ya desde el teatro clásico mediante la acción del coro que se dirige directamente a la platea.

${ }^{7}$ Le Corbusier: La Ville Radieuse; éléments d'une doctrine d'Urbanisme pour l'équipement de la civilisation machiniste. Boulogne-sur-Seine: Éditions de l'Architecture d'aujourd'hui, 1935.
} 
par con dos anotaciones manuscritas sin alusión alguna en el texto ni referencia en ningún otro elemento de la publicación (Imagen 1).

La obra, publicada en el año 1935, y que de manera testimonial y tangencial va a suponer el primer vehículo de publicitación de la herramienta de la cuarta pared, supone un tratado completo de urbanismo de composición heterogénea, en el que las técnicas modernas que han de construir el nuevo modelo de ciudad ocupan una parte importante. Es precisamente en esa segunda parte del libro, Les techniques modernes, más concretamente en la página 44 de su cuarto apartado, La respiration exacte, donde aparecerá el concepto de cuarta pared en forma de ilustración con notas manuscritas.

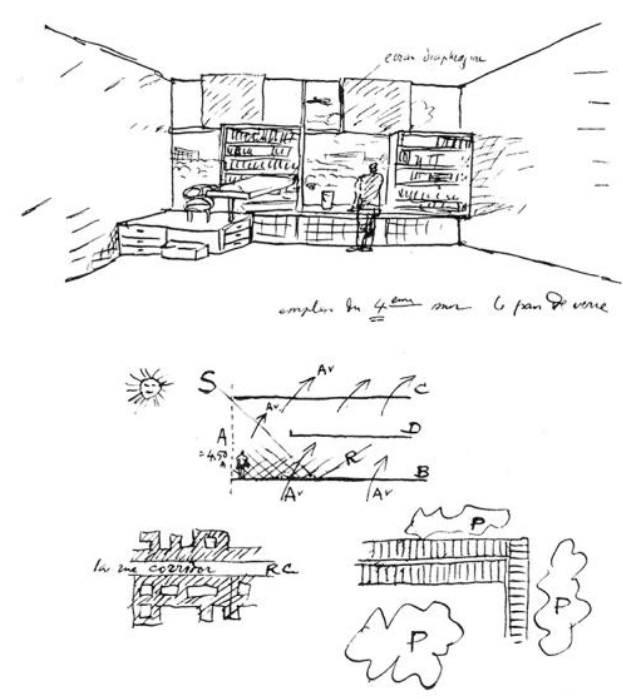

1. Le Corbusier. La Ville Radieuse. OFLC-ADAGP. Croquis inaugural de la teoría de la cuarta pared.

En la ilustración que aparece justificada en el margen izquierdo de la página 44 del libro se distinguen dos partes diferenciadas: en la parte superior se representa una perspectiva frontal de una habitación tipo con un único punto de fuga, introduciendo de manera gráfica el concepto de cuarta pared. En la parte inferior, unos esquemas sitúan en planta y en sección dicha estancia dentro del bloque y describen en sección el impacto de la radiación solar en dicha estancia.

La parte inferior de la imagen es la única que enlaza con el texto del capítulo que acompaña a la ilustración, donde se indica que la fachada será enteramente de vidrio y hermética, quedando la estancia climatizada mediante el sistema de tratamiento de aire de la respiration exacte. La parte superior de la ilustración, la que define el empleo del concepto de le quatriéme mur en el pan de verre, no encuentra referencia alguna en el texto, limitándose su alcance a lo expresado mediante medios gráficos. En este sentido la elección de la vista frontal garantiza por un lado la claridad geométrica y dimensional de lo representado y centra la atención sobre el plano del cerramiento en la abstracción de la estancia arquitectónica universal que define.

El dibujo tal y como aparece reproducido es monocromo y de trazo lineal, la superficie de la ilustración superior es 8 × $5 \mathrm{~cm}$. El trazo a mano alzada tiene un alto grado de detalle, y define una serie completa de códigos, 
elementos y relaciones entre los mismos esenciales para la transmisión de las leyes básicas de la teoría de la cuarta pared. La interpretación del nuevo concepto de quatrième mur depende por tanto del análisis cuidadoso del contenido del croquis.

La característica principal del croquis es la división del pan de verre en fragmentos de distintas medidas, de acuerdo a una geometría ortogonal, no basada en una malla previa homogénea en ninguna de las dos direcciones del plano, similar a la usada por los suprematistas en la división del lienzo en sectores con diferentes características plásticas.

Establecida la división en partes, cada uno de los elementos resultado de la división tiene un tratamiento diferenciado. Cada elemento tiene un grado de transparencia-opacidad, para lo cual el arquitecto se esfuerza en usar los reducidos mecanismos gráficos del dibujo a línea monocromo para dejar claro el material de cada uno de los elementos. Un rayado en cuadrícula representa la franja inferior en vidrio armado, habitual en sus construcciones sobretodo en la parte inferior de los pan de verre de sus proyectos de la época; la ausencia de trazos indica la opacidad de la pieza; y las vistas cercanas o lejanas (paisajes urbanos, nubes, aviones) informan de la transparencia de los distintos elementos.

Adicionalmente, algunos de los módulos en los que se divide el plano de fachada aparecen equipados. Por un lado se introducen elementos tipo casier proyectados en voladizo hacia el interior de la vivienda. Se dibujan alojando libros, mecanismo gráfico que permite subrayar su funcionalidad y aclarar la escala del mismo, si bien el tamaño con el que parecen representados es mayor del habitual en los diseños de Charlotte Perriand de esa misma época. Adicionalmente en la esquina inferior izquierda del mismo se dispone una plataforma materializada por la adición de dos módulos de cajonera que abren hacia dos direcciones diferentes, enfatizando su carácter de ocupación del espacio y de su capacidad de definición de uso del mismo. Junto a la plataforma, un escalón define el acceso a la misma, explicitando la posibilidad de uso de la misma por parte del usuario, representado cerca acogido por el dispositivo espacial que supone el cerramiento de cuarta pared.

Sobre la plataforma equipada se disponen dos elementos de mobiliario estándar: una silla y una mesa. Esta operación define la influencia del cerramiento de cuarta pared sobre el sistema de objetos contenido en la estancia que lo alberga. El cerramiento equipado "imanta" el mobiliario suelto de la habitación, definiendo su posición. Esta polarización transforma de hecho algunos de estos elementos de mobiliario, como en el caso de la mesa que ve reducido su número habitual de apoyos a uno, ya que el tablero de la misma descansa también sobre la balda inferior de uno de los casier incorporados al cerramiento. El elemento trasformado queda por tanto a medio camino entre el objeto de mobiliario independiente (el caso de la silla) y el módulo de equipamiento completamente integrado en el cerramiento (el caso del casier). 
En relación con esta disposición del equipamiento dentro del pan de verre, recientemente Arthur Ruegg en su libro Furniture and Interiors ${ }^{8}$ yuxtapone la imagen de le quatrième mur que nos ocupa a la imagen de la unidad de estudio (plataforma-cajonera, mesa y silla, Imagen 2) de la ampliación de la Maison du Lac del año 1931 y describe el croquis de la cuarta pared como la generalización a la totalidad del pan de verre de la operación de equipamiento llevada a cabo en el cuarto de invitados de la casa. Fija además el origen de la disposición del mobiliario sobre un estrado en los studioli de los cuadros renacentistas, la silla como perteneciente al estudio del padre del arquitecto y la disposición de doble apoyo en pata y muro trasunto de la disposición observada en las celdas de los monjes del Monasterio de Ema.

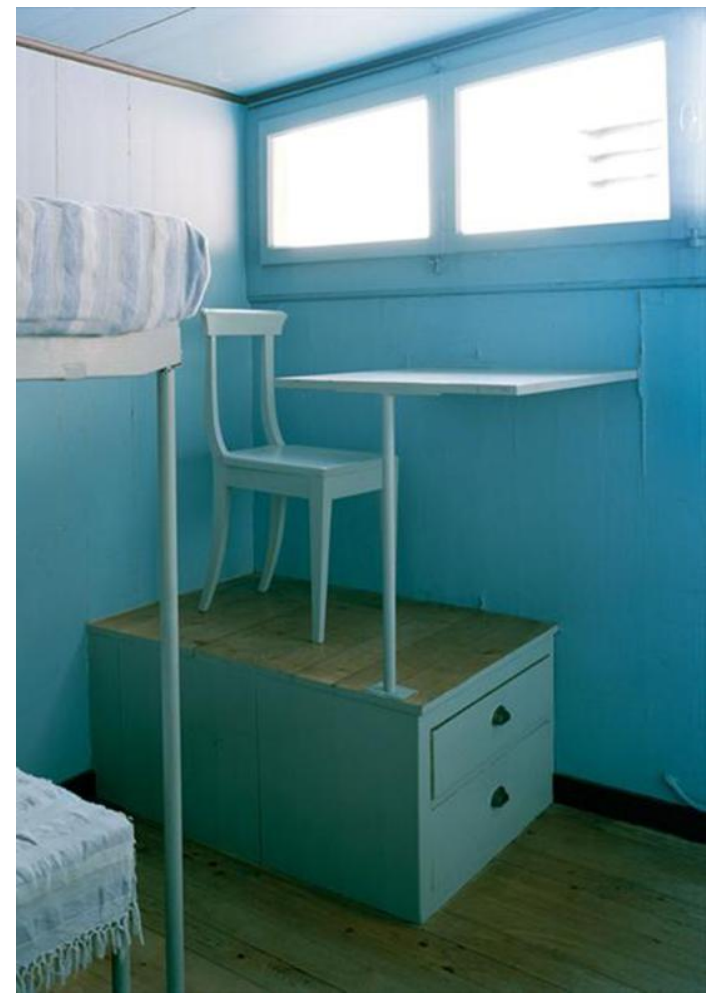

2. Olivier Martin- Gambier, (OFLC-ADAGP. Unidad de estudio de la ampliación de la Maison du lac, 1931

La hipótesis del cambio de escala para la definición de la teoría de la cuarta pared es plausible, si bien la existencia de un croquis (Imagen 3) datado en 1930 perteneciente al proceso de diseño del Proyecto Wanner en el que ya se enuncia la teoría de manera gráfica similar a la que se muestra en el dibujo de La Ville Radieuse publicado en 1935, hace pensar más en un proceso de continuo enriquecimiento del esquema, en el que el croquis aparecido en La Ville Radieuse supondría una versión enriquecida respecto al de 1930, al que se habría incorporado una unidad de estudio completa como la de la ampliación de la Maison du Lac (1931).

Continuando con el análisis de la ilustración, observamos que el pan de verre que representa la figura no es plano, sino que ha adquirido espesor, debido a la introducción de elementos que no le son habituales. Este espesor no queda definido con claridad. En ocasiones parece proyectarse hasta adquirir el espesor de una tabla en continuidad con los costados de los casiers, en otros salvan el desplazamiento de dos partes no coplanarias, como en el caso del estante que se forma entre la base de vidrio armado translucido interior y el hueco transparente inmediatamente superior. En cualquier caso, este crecimiento de grosor permite introducir piezas de

${ }^{8}$ Rüegg, Arthur: Le Corbusier, Furniture and Interiors 1905-1965. Zürich, Verlag Scheidegger and Spiess, 2012, 
equipamiento, dotar de relieve al cerramiento y colocar el vidrio en diferentes posiciones con diversos grados de protección solar.

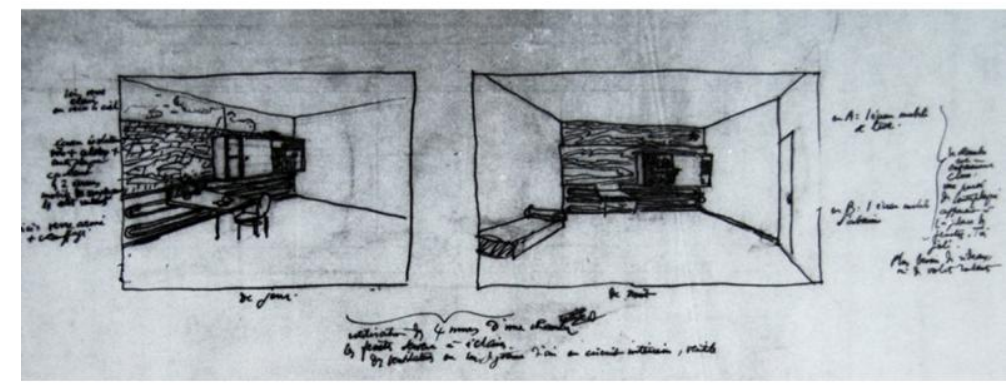

3. Le Corbusier. 8664 OFLC-ADAGP. Cerramiento en clave de cuarta pared en posiciones día-noche perteneciente al proyecto del Immeuble Wanner, 1930

El esquematismo y la simplicidad de la técnica del dibujo no le impide a Le Corbusier introducir apuntes sobre el tipo de iluminación obtenida mediante la disposición del cerramiento de cuarta pared en una estancia tipo. El dibujo de sombras arrojadas localizadas y diversos trazos indicando una cierta tamización de la luz nos indican la capacidad de la cuarta pared de seguir proporcionando luz natural a la vez que protege de la exposición solar excesiva.

Además de los elementos gráficos ya descritos el dibujo cuenta con dos anotaciones manuscritas, de vital importancia para su entendimiento y en definitiva el único ancla del mismo al nombre de la teoría: “l'emploi du quatrième mur dans le pan de verre”, quedando a modo de título o slogan del dibujo y resumiendo su naturaleza. De manera adicional, en la parte superior de la ilustración encontramos una anotación puntual referente a un elemento del dibujo: "écran diaphragme". Ambas son de gran importancia en el entendimiento del contenido de la ilustración. Analicémoslas por partes:

"l'emploi" (empleo, uso): la elección del término nos introduce el carácter de herramienta de la cuarta pared. Se presenta así con entidad de estrategia o proceso de generación de cerramiento. Modo de hacer o conjunto de instrucciones al servicio del arquitecto para la definición de un cerramiento complejo.

"du quatrième mur" (de la cuarta pared): el nombre otorgado a la herramienta es a la vez poético y contundente, ya que enlaza con la abstracción de estancia que representa el dibujo, al mismo tiempo que introduce, a través de sus reminiscencias teatrales, su papel articulador de dos espacios o realidades diversas, el interior de la habitación y el exterior de la ciudad

"dans le pan de verre" (en la fachada de vidrio): la localización de toda la serie de operaciones descritas en el dibujo en la fachada de vidrio describe la preocupación por los problemas que presenta la misma, expuesta al sol y a cuyas consecuencias ya se enfrentado tras la terminación de los trabajos de La Cité de Refuge. El texto del capítulo ya habla de la necesidad de disposición del brise-soleil y de la necesidad de disponer elementos de bloqueo de la radicación solar, lo que enlaza con la segunda inscripción manuscrita de la ilustración: 
"écran" (pantalla o filtro): superpuesto al vidrio, ya sea por su interior o por su exterior. Será estrategia habitual en las cuartas paredes diseñadas por Le Corbusier y adoptará diversas formas constructivas. Mediante la anotación, el arquitecto añade a la teoría una operación de especialización por capas a la de especialización por partes que es más patente en la ilustración.

diaphragme (diafragma): remarca el hecho de que la pantalla es capaz de obturar la apertura del hueco al que corresponde dentro de la cuarta pared en cuestión e introduce el concepto de obturador dentro d ela teoría, que como veremos será algo recurrente.

La desconexión de la imagen del texto con la obra que la acoge no permite sacar más conclusiones que las que son fruto del análisis del dibujo si bien hemos podido comprobar que el conjunto de instrucciones que contiene es fácilmente deducible mediante la observación y análisis de la misma.

\section{Le Corbusier, Euvre complète $1938-46^{9}(1946)$. Primera puesta a punto de la teoría}

Diez años después de la primera aparición pública de la teoría de la cuarta pared, y sin haberse construido ningún pan de verre diseñado según sus parámetros, la teoría es revisitada y puesta al día con la publicación de la conferencia Problèmes de l'ensoleillement, en el cuarto tomo de la obra completa del arquitecto.

En la década transcurrida entre ambas publicaciones, la teoría se ha empleado y con bastante recurrencia además en el trabajo del estudio de la Rue Sèvres. Basta repasar los planos de los proyectos desarrollados en aquella época para encontrar numerosos ejemplos de frentes de vidrio en clave de cuarta pared: Les immeubles locatifs du aménagement de la place de la mairie, Boulogne-sur-Seine, France, (1939), donde el pan de verre se realiza a base de variaciones de piezas estándar tipo casier, los proyectos de Maisons pour ingénieurs et contremaîtres, S.P.A., Lannemezan, France, (1940), donde los frentes de pan de verre equipados en carpintería de madera entre muros de mampostería responden a los dictados de la teoría ya de manera plena y aparecen de manera clara como frentes completos de cuarta pared enclavados en la envolvente estructural, al igual que en los casos de las Unités d'habitation transitoires, (1944) o de la Résidence Peyrissac, domaine agricole, Cherchell, Algérie, (1942). En todos estos casos los frentes de cuarta pared son concebidos como elementos de construcción seca en carpintería de madera y engloban frentes completos a modo de cierre de una estructura realizada en construcción muraria por artesanos locales.

La herramienta goza ya de unos años de puesta en práctica en los proyectos del estudio cuando se publica la conferencia. El texto de la misma supone una recapitulación completa sobre el problema del cerramiento a lo largo de la carrera de Le Corbusier, partiendo de la necesidad intrínseca a su urbanismo construido con sol, espacio y vegetación, de dotar a sus edificios de luz natural a través de la disposición del pan de verre y la consecuente aparición del problema de la exposición solar. La conferencia llega a su punto clave y Le Corbusier centra entonces el problema a resolver: Il faut diaphragmer le pan de verre.

Comienza entonces un repaso pro las soluciones habidas ya en su recorrido arquitectónico: el vuelo de 1,5 metros de los forjados del Immeuble Clarté, Géneve, Suisse (1930), el esqueleto independiente de los frentes de vidrio retranqueados de la Villa Baizeau, Carthage, Tunisie, (1928), las soluciones a tres niveles de logia, lamas y retranqueo de vidrios de Barcelona y las soluciones de logia y de brise-soleil de Alger, puestas en práctica más tarde en Brasil.

\footnotetext{
${ }^{9}$ Le Corbusier: Problèmes de l'ensoleillement . Le brise-soleil. En L'CEuvre complète 1938-46. Zurich: Girsberger, 1946
} 
$\mathrm{Y}$ es entonces cuando introduce en este nuevo paradigma de la superposición de la logia al pan de verre, lo que va denomina una auténtica conquista arquitectónica, "le quatriéme mur": ...cette solution qui s'appelle "brise soleil" porte un nom significatif. En fait, cést un briseur de toutes sortes de difficultés; on lui ajoindra le "brisevent" par la possibilité de constituer des parois hermetiquesvitrées translucides, transparents, opaques si l'on veut. Une conquête architecturale será faite: l'exploitation du quatrième mur de la chambre ${ }^{10}$.Le Corbusier

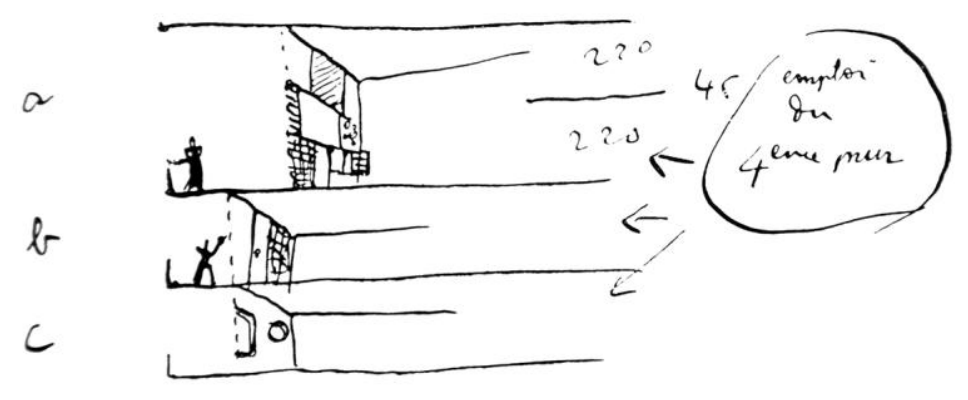

4. Le Corbusier. Euvre complète 1938-46. OFLC-ADAGP. Ilustración que acompaña el texto de la conferencia Problèmes de l'ensoleillement

A partir de ahí desarrolla la explicación de la cuarta pared en dos direcciones, la coincidente con la teoría presentada en La VIlle Radieuse, si bien en este caso son las palabras de Le Corbusier las que describen las operaciones que se pueden realizar en el pan de verre que diez años antes debíamos deducir del análisis de la ilustración y por otro lado la actualización de la teoría al nuevo paradigma de la interposición de la logia habitable, que introduce una nueva variable que transforma en cierta medida la herramienta del quatriéme mur.

La nueva ilustración (Imagen 4) representa una sección esquemática similar a la que ya se presentaba diez años atrás en La Ville Radieuse. De la comparación de ambas descubrimos los nuevos parámetros añadidos al modelo. La cuarta pared ya no se dispone como un cerramiento al borde de la edificación sino que se retranquea, y lo hace en función de la altura del mismo, para optimizar su grado de exposición solar en función de las condiciones higrométricas de la localización donde se trabaje.

En paralelo se establecerá un porcentaje de relación de partes opacas y transparentes en el compacto de cuarta pared que actúa de cerramiento y su valor dependerá también de la orientación y localización del mismo, de la necesidad de bloqueo de la radiación solar. Ambas variables juntas funcionan como un diafragma de una cámara fotográfica, en la que se puede controlar el retranqueo del diafragma y su apertura para encontrar la solución óptima a cada situación de exposición.

Le Corbusier destaca además las ventajas de esta nueva situación, la posibilidad de limpieza con facilidad por parte del usuario del pan de verre, tanto por dentro como por fuera, la posibilidad de que el usuario personalice el frente de su vivienda sin alterar la imagen general del edificio, salvaguardada por el gran orden de logia brisesoleil.

\footnotetext{
${ }^{10}$ Le Corbusier: Problèmes de l'ensoleillement . Le brise-soleil. En L'Euvre complète 1938-46. Zurich: Girsberger, 1946
} 
La nueva incorporación a la cuarta pared, fruto de la nueva posición que ocupa en la edificación, es lo que Le Corbusier denominará trou d'homme, el paso entre el interior de la vivienda y la logia exterior que s e incorporará como un elemento más a las divisiones de la cuarta pared. El pan de verre es por fin practicable, si bien el arquitecto no abandona la idea del mur neutralisant ni de la respiration exacte, que sigue publicitando como posibilidad de instalación en el nuevo orden de fachada de vidrio tras la logia brise-soleil. Si observamos la ilustración que ilustra la conferencia (Imagen 4) donde se representa este juego de retranqueos de los elementos de cuarta pared en función de la altura de la sección, el nivel grafiado con la $c$ se reserva a la solución de mur neutralisant, mientras que los niveles $a$ y $b$ disponen de aperturas y ventilación natural.

\section{Le Modulor $I^{11}(1950)$. Primera presentación de resultados. La reforma del frente oeste de 24NC.}

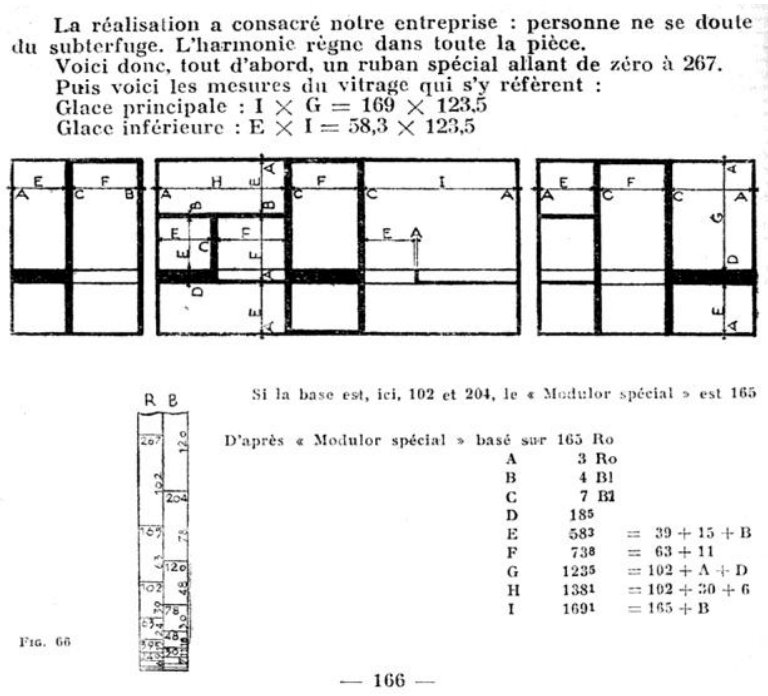

5. Teodoro González de León. Le Modulor. OFLC-ADAGP. Ilustración Une nouveau pan de verre de bois, primera cuarta pared construida.

La publicación del Modulor servirá como vía de propagación del primer resultado construido de la teoría de la cuarta pared. La publicación se limita a presentar la reforma del frente oeste del apartamento del arquitecto como un mero ejemplo de modulación de un frente de vidrio y madera de acuerdo al nuevo sistema de medidas. El proyecto se incluye dentro de la segunda parte del texto, Realidades prácticas, en la selección de proyectos que constituyen el capítulo quinto del libro, Primeros ejemplos de utilización. No menciona el uso de la teoría como tal, ni lo publicita como ejemplo de resultado de la misma. En la representación del mismo se explicitan en un dibujo del cerramiento relleno de negro las medidas del uso del nuevo sistema de medidas, si bien para la ocasión se empleó una escala alterada, Modulor spécial (Imagen 5), ya que por temas normativos la altura del frente a acristalar era de $204 \mathrm{~cm}$. en vez de los 226 canónicos de altura libre que marca la escala canónica del Modulor. El arquitecto, lejos de ver tal eventualidad como un posible síntoma de poca flexibilidad del sistema, lo toma como una prueba de su versatilidad y capacidad de adaptación a distintas situaciones de proyecto. En futuras intervenciones utilizará el Modulor estándar de 226 de manera sistematica.

\footnotetext{
${ }^{11}$ Le Corbusier: Le Modulor: essai sur une mesure harmonique à l'échelle humaine alicable universellement à l'architecture et á la méchanique. Boulogne-sur-Seine: Éditions de l'Architecture d'aujourd'hui, 1950
} 
En el dibujo no se aprecian realmente las operaciones del equipamiento del frente, ni de su potencial como dispositivo capaz de definir el uso del espacio que cierra, los mecanismos gráficos expresivos en esta ocasión potencian el uso de la medida humana en el cerramiento. La publicación sirve por tanto como proyecto hito que pone de manifiesto la voluntad del arquitecto de operar sobre el frente equipado de cuarta pared a escala humana. Las consecuencias derivadas de la introducción del sistema de medida en el uso de la teoría de la cuarta pared en la definición de los cerramientos desde este momento va a ser decisiva principalmente en dos aspectos.

En primer lugar, la utilización de un sistema de medidas a escala humana potenciará en gran medida la facilidad de introducir equipamiento a la medida del usuario con mayor facilidad. Las consecuencias se pueden comprobar desde esta primera aplicación, las medidas de los elementos de la cuarta pared constituida mediante medidas del Modulor dan unidad a todos los elemento sueltos de mobiliario y al equipamiento del frente de vidrio, con lo que la capacidad de la cuarta pared de ordenar el uso del espacio que se define se ve potenciado en gran medida. Este imantado, o ordenación del entorno cercano se va a dar ya en una doble dirección, hacia el exterior de la vivienda y hacia el interior de la misma, actuando como articuladora la cuarta pared de los dos espacios domésticos y poniéndolos en relación, no solo a nivel de circulaciones, comunicación visual y uso de sus respectivos espacios, sino relacionando el equipamiento de ambos, creando una relación visual entre elementos de ambos espacios.

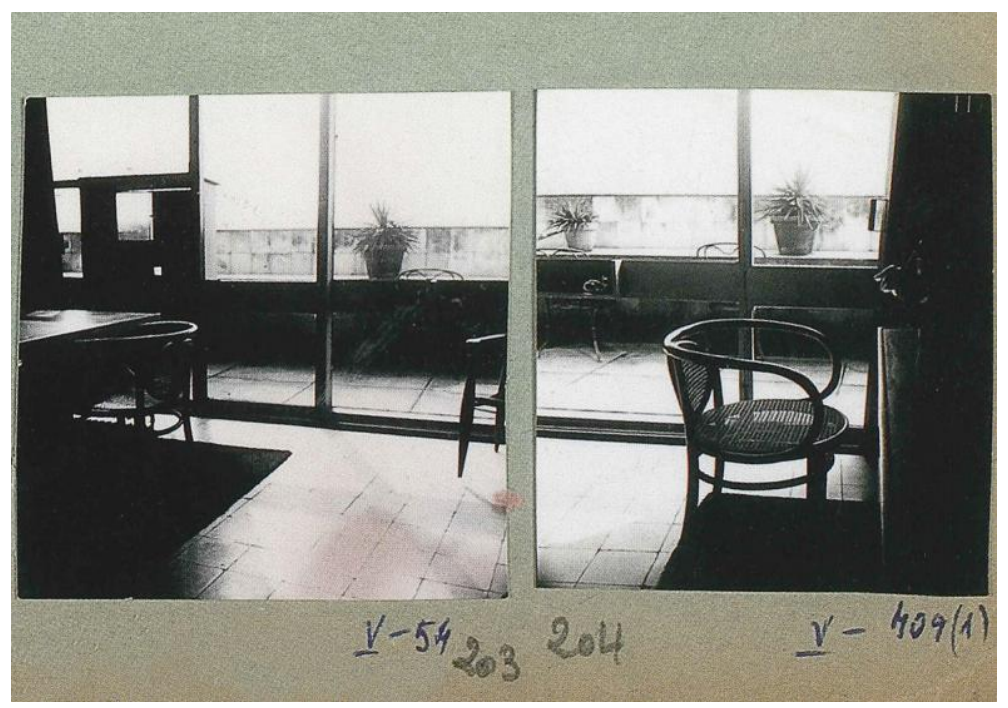

6. Lucien Hervé. OFLC-ADAGP. El frente oeste del apartamento de Le Corbusier

Esto se observa en las imágenes del espacio del comedor del apartamento de Le Corbusier tras la reforma del frente acristalado que nos ocupa (Imagen 6). El elemento de tabla de refuerzo que recorre toda la longitud del cerramiento tiene otra propiedad, y es la de conectar visualmente los planos de la mesa exterior corrida que equipa el peto de la vivienda y la del interior, la mesa de mármol con reborde inspirada en las mesas funerarias egipcias con patas de elefante. La conexión visual hace aparecer el espacio como una verdadera machine à habiter donde todos los elementos encajan, están relacionados visualmente y ordenan el uso que se hace del mismo con precisión.

En segundo lugar la importancia del uso de las medidas del Modulor en la cuarta pared radicará en la rápida sistematización de soluciones que traerá consigo. Este fenómeno no debe entenderse como una pérdida de grados de libertad en las posibilidades de definición de los espacios habitables que cierran los elementos de cuarta pared, sino una progresiva sistematización y optimización de los mismos, que apunta hacia la taylorización 
buscada por el arquitecto. En este sentido es reveladora la lectura de la patente conocida como del Modulor ${ }^{12}$, cuyo nombre real es Breveté Perfectionnements apportés aux ensembles à usage humain constitués para la juxtaposition d'éléments.

La patente define la definición de la escala de medidas y viene acompañada de figuras gráficas a modo de ejemplo. En el texto de la misma se encuentran unas instrucciones breves de cómo aplicar el sistema de medidas a la división de frentes acristalados en cuadrados y rectángulos a los que correspondan materiales diversos e incluso piezas de equipamiento encastradas. Le Corbusier introduce de este modo unas breves instrucciones de cuarta pared en la patente que registra el sistema de medidas del Modulor, quedando su utilización como primera aplicación ligada al nuevo sistema de medidas.

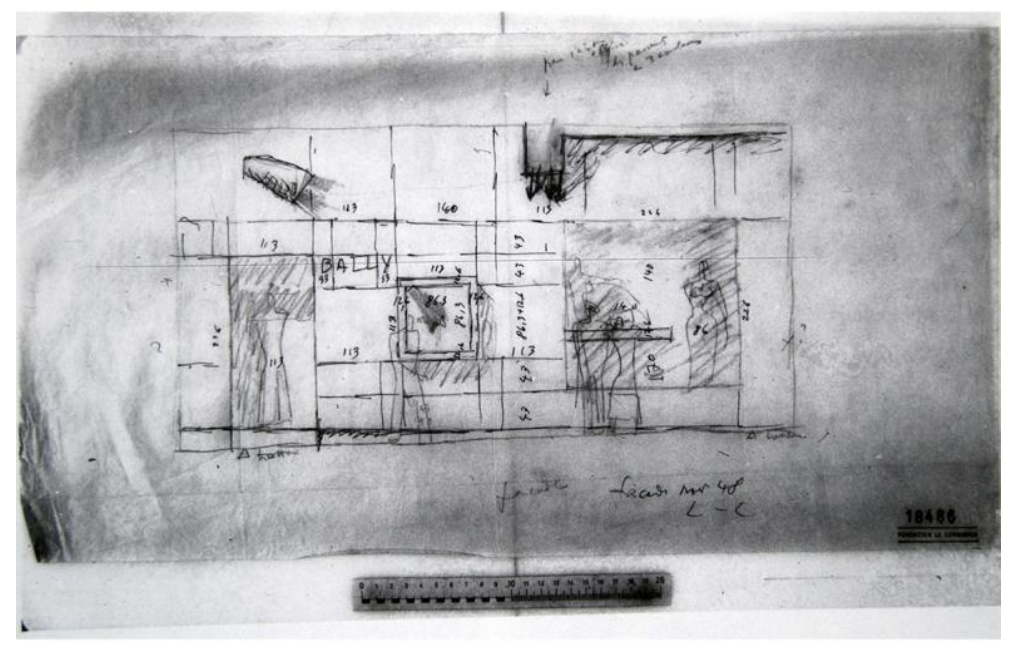

7. Le Corbusier. 18486 OFLC-ADAGP. Estudio de medidas para la fachada del Magasin Bally (1948)

Finalmente, quedaría por citar otro proyecto que aparece publicado en las paginas del Modulor y que en su cerramiento podemos considerar adscrito al modo de hacer de la cuarta pared. Se trata del proyecto del cerramiento del Magasin Bally (1948), que aparece dentro del capítulo 7. Comprobaciones materiales y coda de la publicación. Se trata de un frente para el comercio del Boulevard Madeleine construido en entramado metálico y compartimentado de acuerdo a las medidas del Modulor, donde se abren tres huecos de distintas características, medida, función y posición dentro del espesor del cerramiento (Imagen 7). Se trata de una cuarta pared con todo el juego de posibilidades que la caracteriza, con una mayor proporción de partes opacas respecto a las transparentes debido al uso, diferente al de vivienda y con unas necesidades específicas de exposición, iluminación y control.

${ }^{12}$ Le Corbusier: Breveté Perfectionnements apportés aux ensembles à usage humain constitués para la juxtaposition d'éléments. BSGDG N 996.664 - 15/05/1945, délivré le 05/09/1951, publié le 24/12/1951 


\section{Le Corbusier, Euvre complète $1946-52^{13}$. Segunda presentación de resultados. Los compactos de la fachada de L'Unite de Nantes Rezé. La definición breve de la teoría.}

La siguiente aparición de la cuarta pared en las publicaciones y escritos de Le Corbusier tendrá lugar en el quinto tomo de la obra completa, donde se publica la Unité d'habitation Rezé-les-Nantes (1952-53), en cuyo artículo se dedica una página completa a la reproducción de los cinco elementos tipo prefabricados en madera por el tándem Barberis-Alazard ${ }^{14}$ que se ocupó ya de la construcción de la primera cuarta pared en la reforma del frente oeste del apartamento de Le Corbusier.

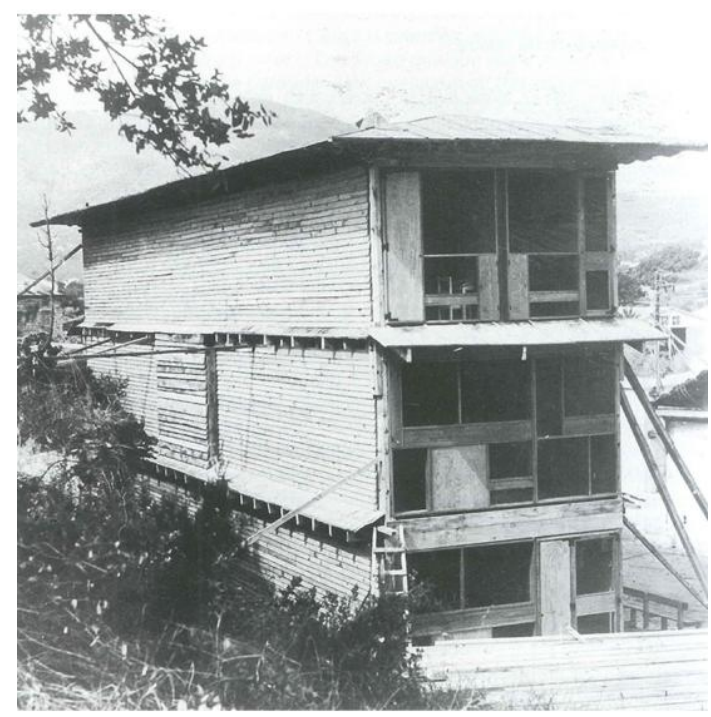

8. OFLC-ADAGP. Prototipo a escala real de los prefabricados de cuarta pared para la Unité de Rezé

El dibujo del alzado de los prefabricados se acompaña de la descripción del espacio de logia anexo y de un breve comentario que aporta dos nuevos datos a añadir al ideario de cuarta pared del que estamos haciendo inventario. En primer lugar Le Corbusier nos da la definición breve de cuarta pared: Le $4^{\text {ème }}$ mur de la pièce: le pan de verre aménagé. La definición mantiene intactas las características que desde el inicio hemos atribuido a la teoría, pero su dimensión más importante está en la amplitud que coge el nombre, y su complemento de la piéce, que nos indica el entendimiento de la pieza de cierre inseparable del espacio que cierra. Ya hemos visto en varias ocasiones que la cuarta pared ordena el espacio que cierra y que desde la llegada del espacio exterior de logia amplía su área de influencia al espacio exterior de la misma manera. La dirección que toma ahora es la de empezar a definir un sistema de módulo habitable y cierre equipado del mismo. En ese sentido la trayectoria del proyecto de L'Unité de Nantes ha supuesto un avance en esa dirección. Las limitaciones económicas del mismo en comparación a Marsella han hecho primar la seriación y simplificación de los elementos de cierre, que se reducen a 5 diferentes, un único compacto para las habitaciones de los niños y dos pares de compactos que configuran el cierre del espacio de salón, dormitorio principal y escalera de manera simétrica.

\footnotetext{
${ }^{13}$ Le Corbusier: Euvre complète 1946-52. Zurich: Girsberger, 1953

${ }^{14}$ EL corso Charles Barberis, carpintero y Jules Alazard antiguo colaborador de Rue de Sévres y a la sazón industrial
} 
De hecho, en el texto que acompaña a la ilustración Le Corbusier recalca que los representados son les seuls éléments standard composant toutes les façades d'appartaments. De esta forma deja claro el valor de la simplificación y optimización de la respuesta en clave de cuarta pared, de máxima economía. Esta depuración afectaba al esquema inicial de la estructura, más cercano si cabe que el finalmente ejecutado al concepto de célula habitable y cierre de la misma con elemento compacto de cuarta pared. El Beru system que finalmente se ejecutó consistía en 2 muros de hormigón ligero de $3 \mathrm{~cm}$ de espesor con $20 \mathrm{~cm}$. interiores de hormigón in situ con armado ligero sobre muros en $\mathrm{M}$ y en V que sustituían a los pilotis originales de Marsella. Las opciones que se barajaron antes seguían el concepto de las boîtes a chaussures, tras el botellero marsellés, una de ellas objeto incluso de una patente, prueba del interés de Le Corbusier por la definición en paralela de la célula habitable y su mecanismo de cierre.

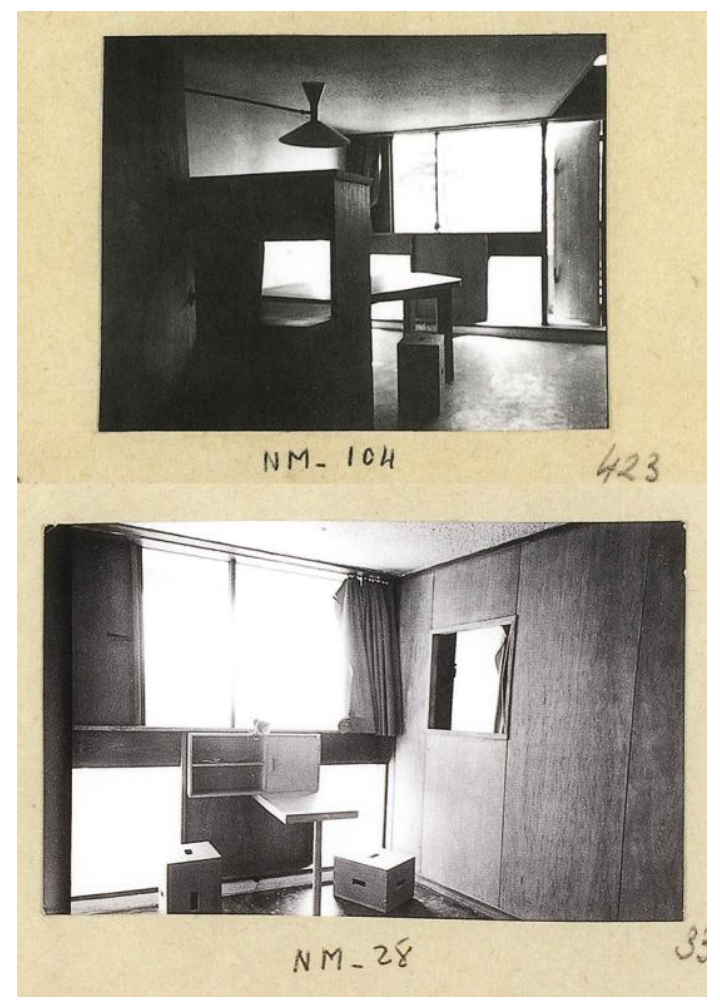

9. Lucien Hervé. (FLC-ADAGP. Vista interior del prefabricado de cuarta pared de las habitaciones infantiles

\section{Modulor $2^{15}(1955)$. Segunda actualización de la teoría y recapitulación.}

La aparición de la teoría en el Modulor 2 sirve de recapitulación de la historia del cerramiento en su obra por parte de le Corbusier reproduciendo un diálogo con Jules Alazard en el que repasan las fases de la evolución del cerramiento en su obra: fenêtre en longeur, pan de verre, le quatriéme mur y le brise-soleil. A estas figuras ya conocidas añade una nueva fase que se identifica con su reciente experiencia india: la separación de funciones.

Al referirse a la cuarta pared realiza un resumen de la misma coincidente con las otras descripciones presentes en su obra, y hace hincapié en el hecho de que la carpintería se realiza en madera ${ }^{16}$ a base de tablas de canto, en

\footnotetext{
${ }^{15}$ Le Corbusier: Modulor 2 (La parole est aux usagers) Suite de "Le Modulor 1948”. Boulogne-sur-Seine: Éditions de l'Architecture dàujourd 'hui, 1955

${ }^{16}$ La elección de la madera como material para la construcción de los frentes de pan de verre, enmarcado en la escasez de acero de la posguerra, momento que supone el pistoletazo de salida para los proyectos fundamentales del arquitecto tiene
} 
vez de tratarse de un bastidor plano, lo que da rango de mobiliario al cerramiento de la vivienda. Destaca además que su disposición bajo al protección de la logia brise-soleil permite que la madera no sea afectada por la lluvia ${ }^{17}$ y su mantenimiento sea sencillo y realizable por el propio usuario.

El diálogo entre Le Corbusier y Jules Alazard tiene lugar a la salida de la visita de obra de las Maisons Jaoul ${ }^{18}$, la obra en la que la estrategia de la cuarta pared junto a la definición de una estructura alveolar 226x226 constituye ya la estrategia completa del proyecto, elevando la teoría de la cuarta pared a tema principal en la definición de su arquitectura.

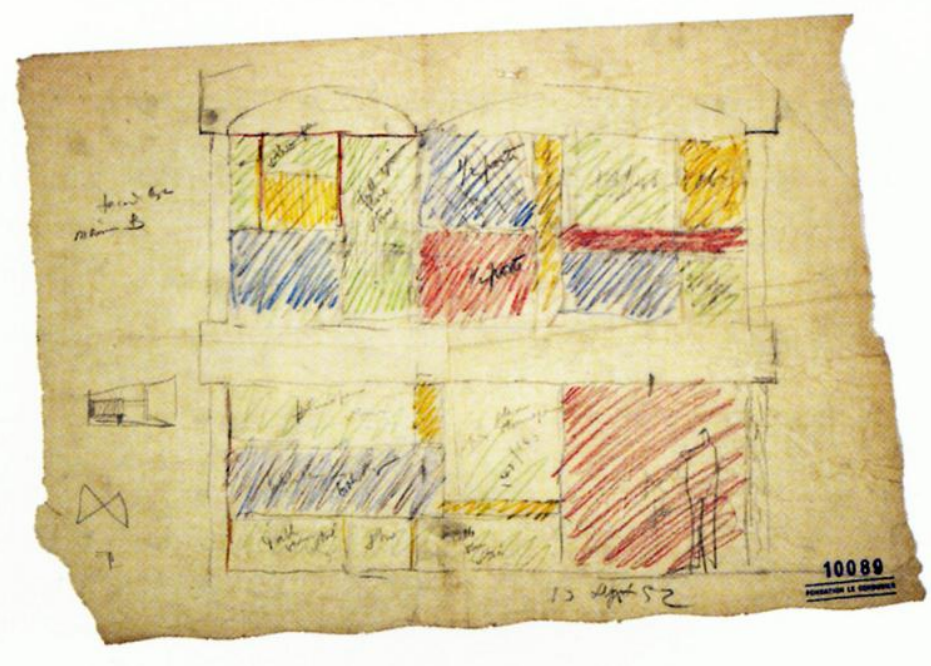

10. Le Corbusier. 10089 @FLC-ADAGP

El último punto de la evolución narrada por el arquitecto se refiere a la separación de funciones de iluminar y ventilar que define el arquitecto en uno de sus viajes a al India tras una toma de datos en el hotel Taj Mahal y que recoge en el Carnet Nivola II (Imagen 11). En él establece un nuevo modelo de quatriéme mur que hace un tratamiento del frente de pan de verre mediante una triple aproximación:

efectivamente un papel fundamental en la utilización de la teoría de la cuarta pared, que se adapta con facilidad a la versatilidad de ese material y potencia su carácter de mobiliario

${ }^{17} \mathrm{El}$ cerramiento del frente oeste de su apartamento, expuesto a la lluvia, sí se vio afectado, la madera se pudrió y el agua entraba en la cámara del acristalamiento y en el año 1962 se sustituyó por otro en aluminio. Existe constancia de una petición de presupuesto de brise-soleil prefabricado para la protección del frente de madera tras su construcción, pero nunca fue llevado a cabo.

${ }^{18}$ El frente oeste de 24NC, les Maisons Jaoul y L'Unité Nantes, las tres llevadas a cabo por el tándem Barberis-Alazard forman lo que podríamos denominar un cánon de quatriéme mur, respondiendo a tres escalas, la del tratamiento independiente de un frente en clave de cuarta pared, la de hacer de la cuarta pared la estrategia general de proyecto y la de seriación de los módulo de cerramiento. 


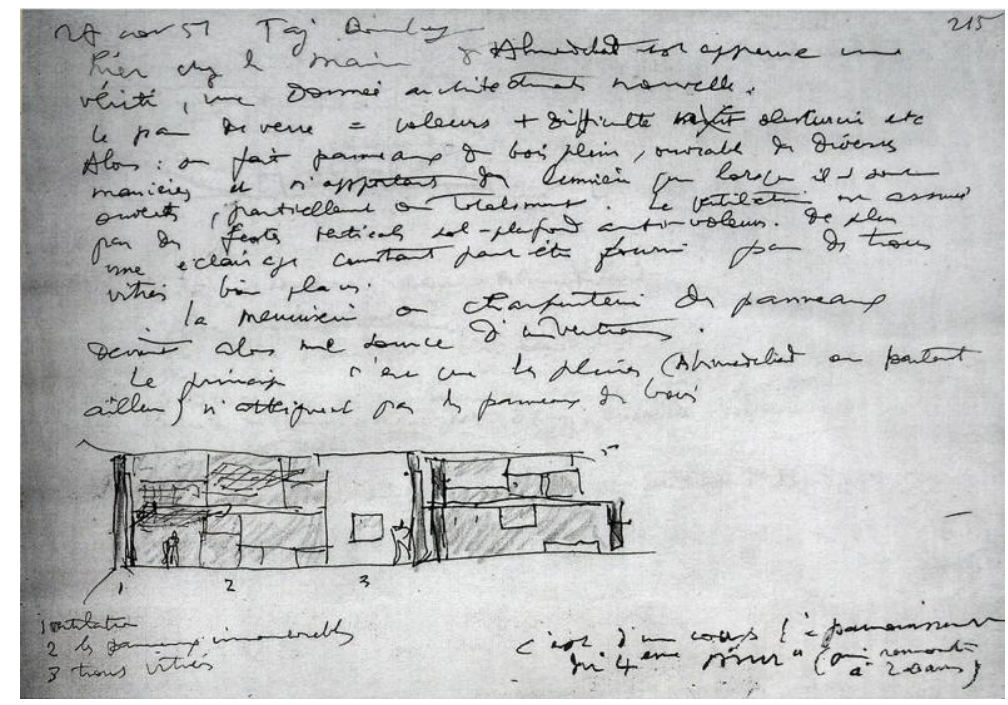

11. Le Corbusier. OFLC-ADAGP. Manuscrito Carnet Nivola II cuya ilustración aparece en el Modulor 2.

Alors: on fait panneaux du bois plein, ouvrables des diverses manières et n'apportant du lumière que lorsque ils sont ouverts, partiellement ou totalement. La ventilation est assuré par des fentes verticales sol-plafond antivoleurs. De plus un éclairage constant peut être fourni par des trous vitrés bien placés. La menuiserie ou charpenterie des panneaux devient alors une source d'inventions.

1 Iluminación mediante paneles practicables

2 Ventilación asegurada por ranuras verticales de suelo a techo anti ladrones

3 Iluminación constante a través de huecos con vidrio fijo

Esta disposición, además de introducir en el catálogo de Le Corbusier la solución de aérateur supondrá la base de la composición del cerramiento de sus proyectos indios, en especial de las villas de Ahmedabad.

\section{De la fenêtre au pan de verre dans làrchitecture de Le Corbusier ${ }^{19}(1959)$. La voluntad de industrialización del sistema.}

A modo de epílogo de la deriva de le quatriéme mur en el universo teórico de Le Corbusier, en 1959 se publica una versión "en limpio" de la evolución del cerramiento en su obra referida en el Modulor 2, supervisada por el arquitecto y realizada a modo de publicación promocional empresarial por Jules Alazard.

La publicación, bajo el título De la fenêtre au pan de verre dans làrchitecture de Le Corbusier presenta documentada con las referencias habituales ya vistas en publicaciones anteriores la evolución en 5 fases ya vista en el Modulor 2. La única aportación o diferencia respecto a su precedente es que la última fase, la separación de funciones no se ilustra ya con el croquis indio que dio lugar al aérateur, sino que viene representado con la definición de unos módulos de quatriéme mur 226 x 226 que presentan la consabida separación de funciones en distintos elementos (ventana transparente para iluminar el área de trabajo, aérateur opaco y verical de suelo a techo, hueco de paso a la logia exterior, hueco de iluminación inferior translúcido, etc) Estos compactos (Figura 12) son la depuración y síntesis de los utilizados en proyectos de la década anterior: Roq et Rob, la celda de la

\footnotetext{
${ }^{19}$ Jules Alazard: De la fenêtre au pan de verre dans l'œuvre de Le Corbusier: étude conçue et rédigée avec l'accord de Le Corbusier. Paris: Dunod, 1959
} 
Tourette, la versión de proyecto de la habitación de estudiante de la Maison du Brasil por citar los más significativos. (Imágenes 13, 14 y 15)

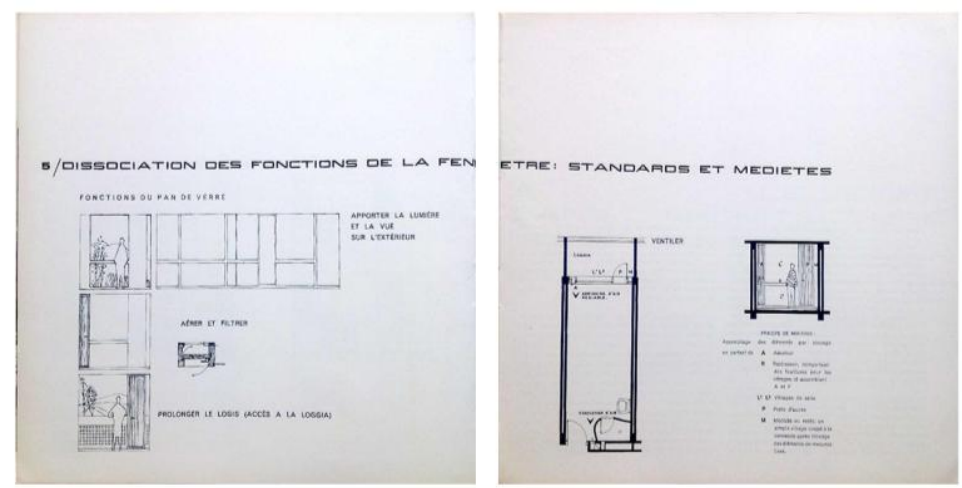

12. Le Corbusier. OFLC-ADAGP. Capítulo 5 del libro De la fenêtre au pan de verre dans l'œuvre de Le Corbusier. Definición de compacto de cuarta pared 226×226 con separación de funciones

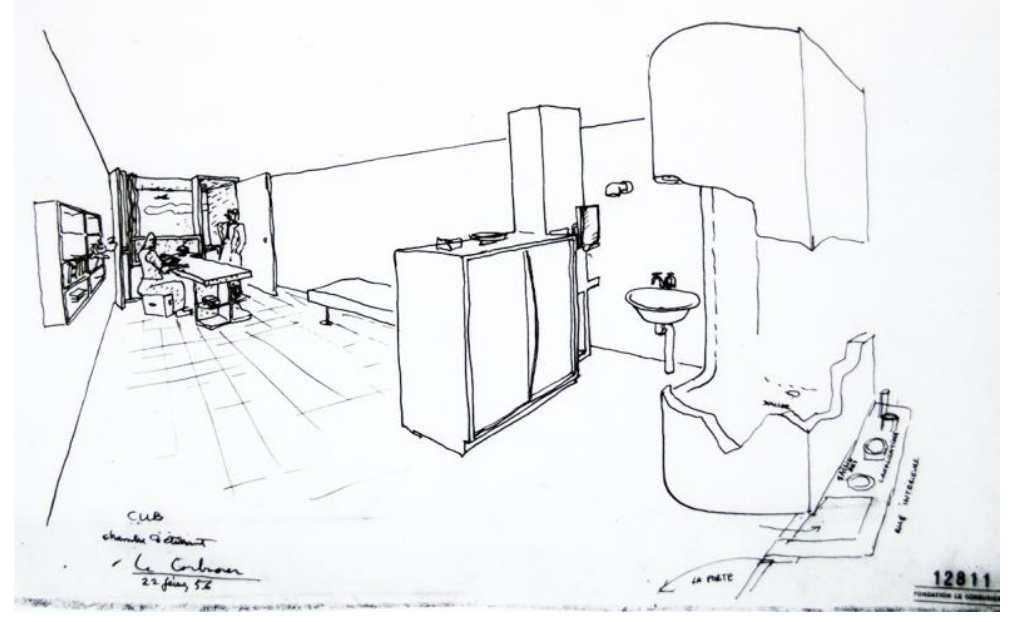

13. Le Corbusier. 12811 CFLC-ADAGP. Versión de proyecto de los cerramientos de las habitaciones de estudiantes de la Maison du Brésil.

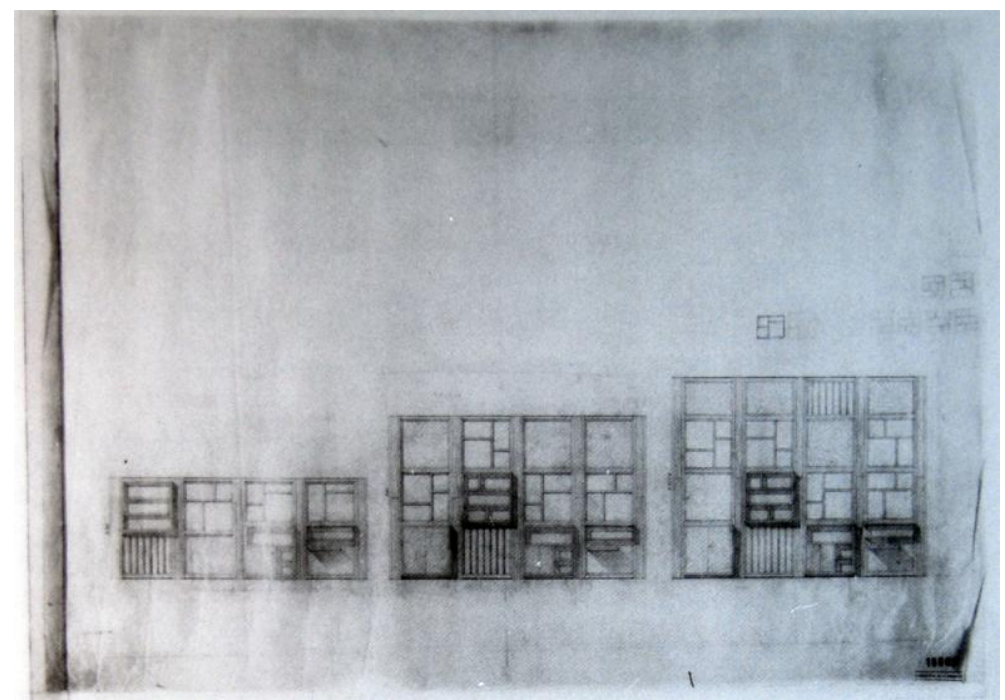

14. Le Corbusier. 18867 OFLC-ADAGP. Estudio de fachadas en compactos de cuarta pared 226 x 226 para Roq et Rob. 


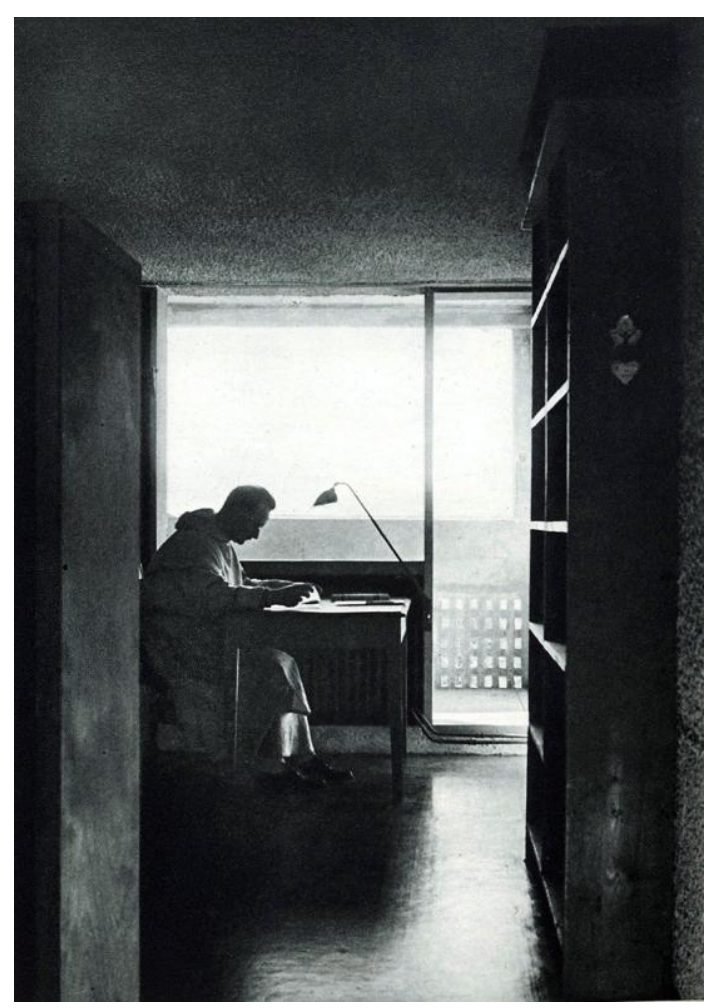

15. J.Caps. L'Art Sacré, "Le Corbusier: Un couvent dominicain”, Mars-Avril 1960, nº-8. Paris: Éditions du Cerf, 1960. pp 21-32. Un dominico estudia en la cuarta pared de su celda.

El origen de este dibujo se encuentra en el acta de una reunión que mantuvieron el industrial y el arquitecto, En ella se puede leer: 27 juillet 57. 24NC Jules Alazard + L-C. Thème: Le 4ème mur, Éléments type L-C \& mettre en vente. Conclussion: L'Unité modular est 226/226.

El contenido del acta deja claro el entendimiento por parte del arquitecto de un sistema de producción de soluciones habitacionales a base de la doble componente de estructura alveolar 226/226 y compactos de cerramiento tipo quatriéme mur. Se dejan además dibujados con indicaciones para su elaboración posterior e inclusión en la publicación del industrial con vistas a su comercialización. Es la culminación de un proceso de depuración de las soluciones de cuarta pared comenzado con un dibujo en La Ville Radieuse.

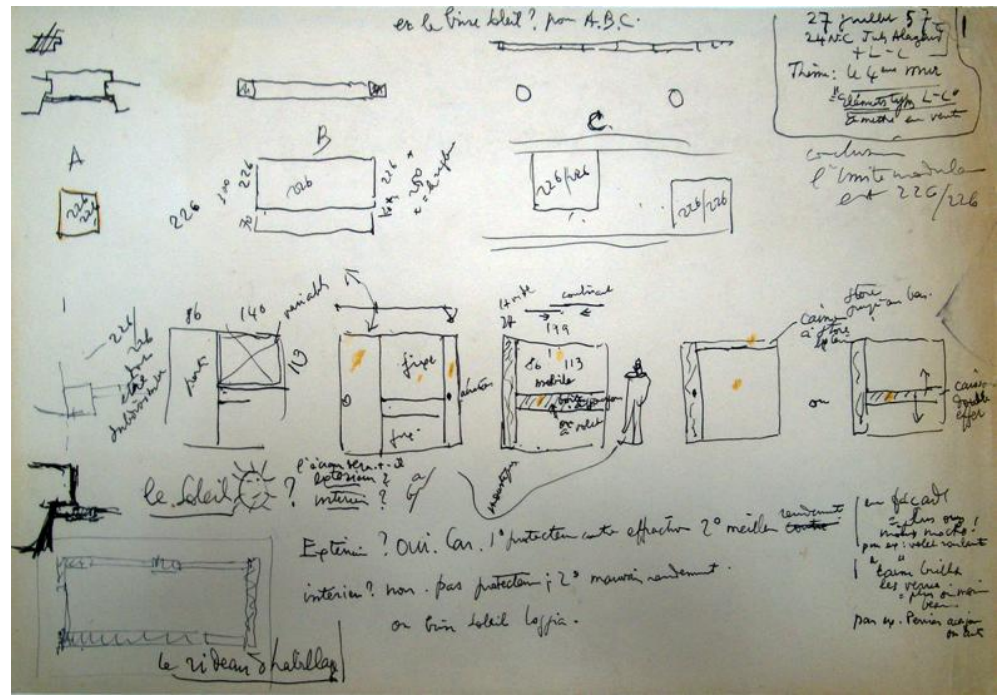

16. Le Corbusier. Centro Canadiense de Arquitectura. Acta Reunión. Tema: L $4{ }^{\text {ème }}$ mur "Elements type L-C" \& mettre en vente. Asistentes: Le Corbusier, Jules Alazard. Lugar: Apartamento de Le Corbusier, 24NC, Paris. Fecha: 27 julio 1957. 


\section{Conclusiones}

El recorrido establecido desde la primera aparición de la teoría en La Ville Radieuse hasta el acta de la reunión en $24 \mathrm{NC}$ con Jules Alazard nos ha permitido entender el papel de la teoría de la cuarta pared como aglutinador de técnicas referidas al cerramiento de la edificación con el pan de verre. El repaso de los documentos relativos a la teoría ha servido para identificar las instrucciones de la herramienta de proyecto de cuarta pared y que se resumen en tres grandes grupos: operaciones de especialización del cerramiento por partes mediante la división del cerramiento de acuerdo a la geometría del Modulor; operaciones de especialización por capas mediante la superposición de pantallas y por último operaciones de especialización funcional mediante la incorporación de equipamiento.

Los elementos de cierre de cuarta pared actúan como dispositivos de la máquina de habitar con dos funciones principales:

- La primera función es la de definir el uso espacial de la célula habitable que cierran, articulando la relación interior y exterior, asimilando en su interior el equipamiento esencial de la pieza y ordenando el resto de mobiliario.

- La segunda es la de actuar como diafragmas, y en conjunción con el elemento exterior de logia adoptar un grado de opacidad y un retranqueo suficientes para conjugar las necesidades de la pieza ofreciendo la protección solar que la orientación y situación de la misma demandan

Finalmente la teoría de la cuarta pared junto con la investigación paralela de una estructura alveolar 226/226 configuran un sistema de producción del hábitat a escala humana.

\section{Procedencia de las imágenes}

Imagen 1. Le Corbusier. La Ville Radieuse. CFLC-ADAGP. Croquis inaugural de la teoría de la cuarta pared.

Imagen 2. Olivier Martin- Gambier, CFLC-ADAGP. Unidad de estudio de la ampliación de la Maison du lac, 1931

Imagen 3. Le Corbusier. 8664 CFLC-ADAGP. Cerramiento en clave de cuarta pared en posiciones día-noche perteneciente al proyecto del Immeuble Wanner, 1930.

Imagen 4. Le Corbusier. Euvre complète 1938-46. CFLC-ADAGP. Ilustración que acompaña el texto de la conferencia Problèmes de l'ensoleillement

Imagen 5. Teodoro González de León. Le Modulor. CFLC-ADAGP. Ilustración Une nouveau pan de verre de bois, primera cuarta pared construida.

Imagen 6. Lucien Hervé. CFLC-ADAGP. El frente oeste del apartamento de Le Corbusier

Imagen 7. Le Corbusier. 18486 CFLC-ADAGP. Estudio de medidas para la fachada del Magasin Bally (1948)11

Imagen 8. CFLC-ADAGP. Prototipo a escala real de los prefabricados de cuarta pared para la Unité de Rezé. 12

Imagen 9. Lucien Hervé. CFLC-ADAGP. Vista interior del prefabricado de cuarta pared de las habitaciones infantiles 
Imagen 11. Le Corbusier. CFLC-ADAGP. Manuscrito Carnet Nivola II cuya ilustración aparece en el Modulor 2.

Imagen 12. Le Corbusier. CFLC-ADAGP. Capítulo 5 del libro De la fenêtre au pan de verre dans l'œuvre de Le Corbusier. Definición de compacto de cuarta pared 226×226 con separación de funciones. 16

Imagen 14. Le Corbusier. 12811 CFLC-ADAGP. Versión de proyecto de los cerramientos de las habitaciones de estudiantes de la Maison du Brésil.

Imagen 13. Le Corbusier. 18867 CFLC-ADAGP. Estudio de fachadas en compactos de cuarta pared 226 x 226 para Roq et Rob.

Imagen 15. J.Caps. L'Art Sacré, "Le Corbusier: Un couvent dominicain”, Mars-Avril 1960, n7-8. Paris: Éditions du Cerf, 1960. pp 21-32. Un dominico estudia en la cuarta pared de su celda.

Imagen 16. Le Corbusier. Centro Canadiense de Arquitectura. Acta Reunión. Tema: L 4 ème mur "Elements type L-C" \& mettre en vente. Asistentes: Le Corbusier, Jules Alazard. Lugar: Apartamento de Le Corbusier, 24NC, Paris. Fecha: 27 julio 1957.

\section{Bibliografía/referencias}

Gargiani, Roberto; Rosellini, Anna: Le Corbusier: Béton Brut and Ineffable Space, 1940-1965 : Surface Materials and Psychophysiology of Vision. Lausanne: EPFL Press - Oxford: Routledge, 2011

Jules Alazard: De la fenêtre au pan de verre dans l'œuvre de Le Corbusier: étude conçue et rédigée avec l'accord de Le Corbusier. Paris: Dunod, 1959

Le Corbusier: Breveté Perfectionnements apportés aux ensembles à usage humain constitués para la juxtaposition d'éléments. BSGDG N 996.664 - 15/05/1945, délivré le 05/09/1951, publié le 24/12/1951

Le Corbusier: La Ville Radieuse; éléments d'une doctrine d'Urbanisme pour l'équipement de la civilisation machiniste. Boulogne-sur-Seine: Éditions de l'Architecture d'aujourd'hui, 1935

Le Corbusier: Le Modulor: essai sur une mesure harmonique à l'échelle humaine alicable universellement à l'architecture et á la méchanique. Boulogne-sur-Seine: Éditions de l'Architecture d'aujourd'hui, 1950

Le Corbusier: Modulor 2 (La parole est aux usagers) Suite de "Le Modulor 1948”. Boulogne-sur-Seine: Éditions de l'Architecture dàujourd'hui, 1955

Le Corbusier: Euvre complète 1938-46. Zurich: Girsberger, 1946

Le Corbusier: Euvre complète 1946-52. Zurich: Girsberger, 1953

Le Corbusier: Problèmes de l'ensoleillement . Le brise-soleil. En Techniques et architecture VOL VI, 1946, N¹$1, \mathrm{pp} 26-28$

Maniaque, Caroline: Le Corbusier et Les maisons Jaoul. Projets et fabrique Paris: Éditions A. \& J. Picard, 2005

Martínez Arroyo, Carmen: "La densidad del límite". En Arquitectos nº174, Volumen 05/2. Madrid: CSCAE 2005

Martínez Arroyo, Carmen: La densidad del limite. Le Corbusier y Mies Van Der Rohe del equipamiento al sistema de objetos. Director: Manuel de las Casas. Universidad Politécnica de Madrid, Escuela Técnica Superior de Arquitectura de Madrid, Departamento de Proyectos Arquitectónicos, 2005

Rüegg, Arthur, Le Corbusier, Furniture and Interiors 1905-1965. Zürich, Verlag Scheidegger and Spiess, 2012

Sbriglio, Jacques, Immeuble 24 N.C. et Appartement Le Corbusier. Basel: Birkhäuser, 1996 